УДК 591.524.1(262.5)

\title{
МАКРОЗООБЕНТОС ЗОНЫ ПСЕВДОЛИТОРАЛИ КРЫМСКИХ ЗАПОВЕДНИКОВ
}

\section{Копий В.Г.}

ФГБУН «Институт морских биологических исследований имени А.О. Ковалевского РАН», 2. Севастополь, Российская Федераиия, е-таil:verakopiy@gmail.com

В основу работы положены материалы, собранные на участках псевдолиторали Карадагского (июль 2008 г.), Казантипского, Опукского (август 2013), «Мыс Мартьян» (август 2014 г.) природных заповедников. На основе обобщения полученных данных представлен таксономический и видовой состав макрозообентоса псевдолиторали заповедников Крыма, дана краткая характеристика доминирующих видов. Проведен сравнительный анализ количественных параметров макрозообентоса, исследовано горизонтальное распределение животных относительно уреза воды и трофическая структура сообществ макрозообентоса зоны псевдолиторали крымских заповедников.

Ключевые слова: макрозообентос, псевдолитораль, заповедники Крыма, Черное море.

\section{Введение}

Прибрежные участки моря испытывают наиболее интенсивное воздействие неблагоприятных природных и антропогенных факторов, которое приводит к деградации сообществ и снижению биоразнообразия. Кроме этого, прибрежные сообщества первыми реагируют даже на незначительные изменения и поэтому могут выступать в роли биоиндикаторов. Несмотря на то, что краевые сообщества играют существенную роль в процессах трансформации веществ и энергии, они, к настоящему времени, остаются наименее изученными (Зайцев, Поликарпов, 2002; Киселева и др., 2009; Миронов, 2009; Гринцов, Лисицкая, 2016).

В нашей работе исследован макрозообентос зоны псевдолиторали четырех природных заповедников, которые отличаются географическим положением, степенью воздействия негативных факторов, гидрологическими характеристиками, различным гранулометрическим составом грунта и др.

Заповедник «Мыс Мартьян» организован по Постановлению Совета Министров УССР № 84 от 20.02.1973 г. Прибрежье мыса Мартьян является одним из немногих сохранившихся естественных участков с типичной донной растительностью. Территория заповедника представляет собой относительно пологий макросклон, заканчивающийся у берега обрывом из известняков и сцементированных брекчий. Пляжевые полосы состоят в основном из мраморовидного известняка. Район характеризуется приглубыми берегами, постоянным и сильным волнением, типичным для открытого моря (Маслов и др., 2011; Садогурсська, 2013).

Карадагский природный заповедник создан по Постановлению Совета Министров УССР 9 августа 1979 г. В 80-е годы прошлого столетия акватория заповедника обладала чистой морской водой. Но с развитием курортного бизнеса в акваторию заповедника с поселков Коктебель и Курортное увеличилось поступление недоочищенных бытовых вод, которое привело к ухудшению качества воды и уменьшению ее солености. По литературным данным известно, что к 2007 году показатели $\mathrm{pH}$ оставались в норме, а содержание органических веществ превышало ПДК на 30-60\% (Морозова и др., 2007).

Опукский природный заповедник основан в 1998 г. по Указу Президента Украины от 12.05.98 г. № 459/98. Для Опукского массива характерен подвижный приморский 
известково-равнинный тип рельефа, обусловленный смещениями известняков по подстилающим глинам. Склоны Опука срезаны временно стабильными и активными оползнями, состоящие из известняковых блоков, глин и щебнистых суглинков (Загороднюк, 2009).

Казантипский природный заповедник образован 12 мая 1998 г. по Указу Президента Украины. В мелких бухточках Казантипского залива сочетаются скалистые, уходящие в глубину мыски с песчаными пляжами между ними (Зенкович, 1958). Мыс Казантип находится на берегу Азовского моря, в котором происходит смешение речных и черноморских вод, поэтому среднее значение солености воды ниже, чем в Черном море и в среднем составляет 10.9\%о (Грѐзе и др., 1987). Для Азовского моря характерны пространственная изменчивость термических условий, солености и концентрации биогенных веществ. Гидрологические и гидрохимические характеристики, обусловленные мелководностью и географическим положением, носят временный характер (Мурина и др., 2006).

Заповедники - особые участки территорий и акваторий, на которых сохраняется в естественном состоянии весь природный комплекс, поэтому исследование таких участков вызывает определенный интерес.

Цель данной работы - сравнительный анализ таксономического состава и количественных показателей макробентоса зоны псевдолиторали заповедников Крыма.

\section{Материалы и методы}

В основу работы положены материалы, собранные на участках псевдолиторали Карадагского (июль 2008 г.), Казантипского, Опукского (август 2013), «Мыс Мартьян» (август 2014 г.) природных заповедников (рис. 1).

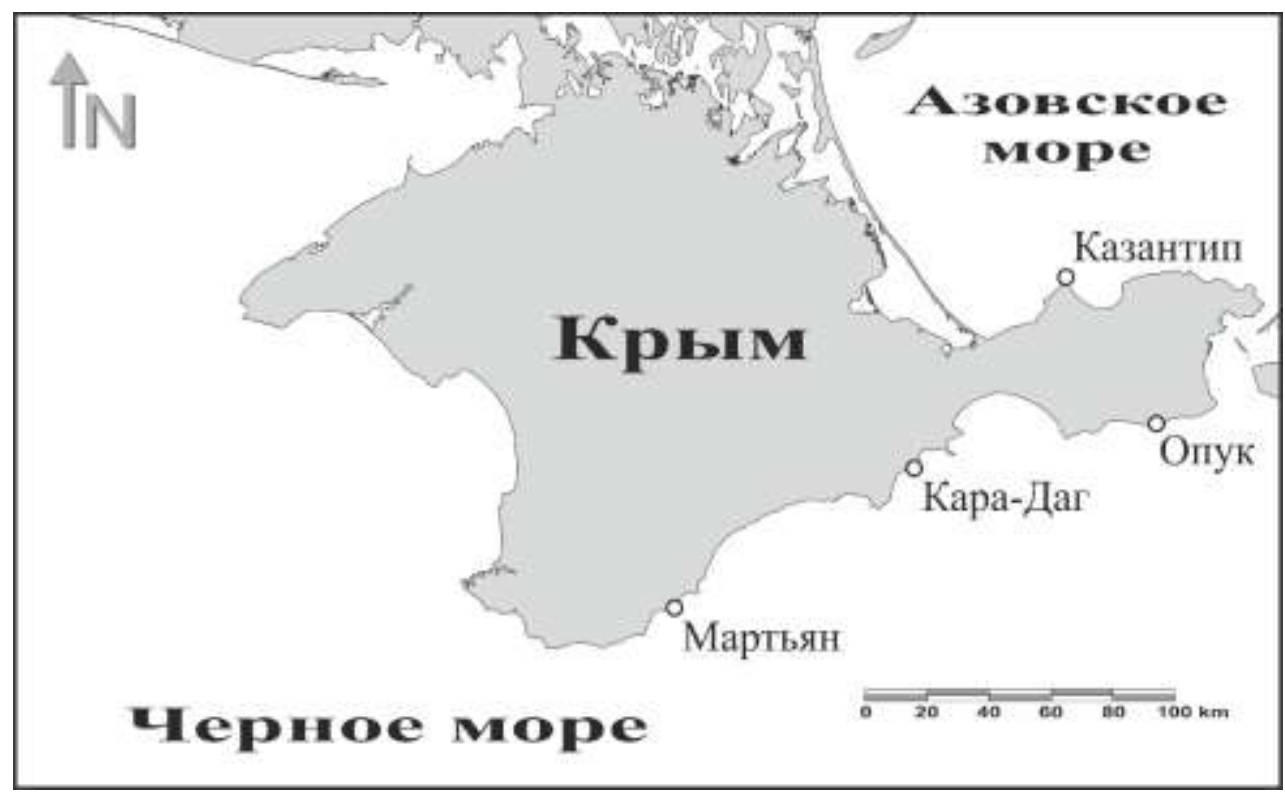

Рис. 1. Карта-схема районов исследования.

Пробы отбирали на участке псевдолиторали - прибойной зоны, расположенной в границах колебания прибойных волн, при этом верхняя граница псевдолиторали проходит по верхнему краю максимального заплеска, а нижней является отсыпь пляжа (Мокиевский, 1949). Сбор материала проводился ручным дночерпателем $\left(\mathrm{S}=0.4 \mathrm{~m}^{2}\right)$ в двух повторностях. На каждом разрезе, расположенном перпендикулярно берегу, пробы 
отбирали в пяти точках: в зоне уреза воды, ниже уреза воды на 0.5 и 1 м и выше уреза воды на 0.5 и 1м. Урезом воды считали среднюю линию между верхним и нижним краями заплеска.

Всего было взято 258 количественных проб. В лабораторных условиях пробы промывали через сито с диаметром ячеек 0.5 мм и фиксировали 4\%-ным раствором формалина. Затем материал разбирали по группам: Polychaeta, Mollusca, Crustacea, Oligochaeta, Platyhelminthes и Nemertea. При описании количественного развития фауны использованы показатели численности $\left(\mathrm{N}\right.$, экз $\left./ \mathrm{M}^{2}\right)$ и биомассы $\left(\mathrm{B}, \Gamma / \mathrm{M}^{2}\right)$.

\section{Результаты и обсуждение}

В исследуемой зоне идентифицированы представители макрозообентоса, относящиеся к разным таксономическим категориям: Polychaeta, Mollusca Crustacea, Platyhelminthes, Nemertea, Oligochaeta (табл. 1).

Таблица 1.

Средние значения численности (экз/ $\left.\mathbf{M}^{2}\right)$ и биомассы $\left(г / \mathbf{M}^{2}\right)$ представителей макрозообентоса заповедников Крыма (зона псевдолиторали)

\begin{tabular}{|c|c|c|c|c|}
\hline \multirow{2}{*}{ Таксон } & \multicolumn{2}{|c|}{ Мыс Мартьян } & \multicolumn{2}{|c|}{ Карадаг } \\
\hline & $\mathrm{N}$ & $\mathrm{B}$ & $\mathrm{N}$ & $\mathrm{B}$ \\
\hline Polychaeta & $9 \pm 7$ & $2.09 \pm 1.13$ & $1725 \pm 561$ & $3.679 \pm 1.149$ \\
\hline Crustacea & $2473 \pm 810$ & $1.72 \pm 0.55$ & $521 \pm 183$ & $0.335 \pm 0.100$ \\
\hline Platyhelminthes & $6 \pm 4$ & $0.001 \pm 0.0007$ & $220 \pm 56$ & $0.052 \pm 0.016$ \\
\hline Nemertea & 0 & 0 & $213 \pm 101$ & $2.08 \pm 0.963$ \\
\hline ИТОГО & $2479 \pm 808$ & $1.722 \pm 0.567$ & $2678 \pm 859$ & $6.146 \pm 2.029$ \\
\hline Таксон & \multicolumn{2}{|c|}{ Опук } & \multicolumn{2}{|c|}{ Казантип } \\
\hline Polychaeta & $202 \pm 101$ & $0.054 \pm 0.042$ & 0 & 0 \\
\hline Mollusca & $6 \pm 4$ & $2.141 \pm 1.628$ & 0 & 0 \\
\hline Crustacea & $1 \pm 0.5$ & $0.001 \pm 0.0007$ & $121 \pm 82$ & $0.067 \pm 0.038$ \\
\hline Oligochaeta & $55 \pm 24$ & $0.002 \pm 0.001$ & $46 \pm 29$ & $0.0006 \pm 0.0003$ \\
\hline Platyhelminthes & $252 \pm 196$ & $0.022 \pm 0.017$ & $29 \pm 16$ & $0.002 \pm 0.0007$ \\
\hline Nemertea & $55 \pm 31$ & $0.004 \pm 0.002$ & 0 & 0 \\
\hline ИТОГО & $571 \pm 396$ & $2.225 \pm 1.644$ & $195 \pm 89$ & $0.069 \pm 0.038$ \\
\hline
\end{tabular}

Примечание: средние величины представлены с погрешностью 95\% доверительного интервала.

Средние значения численности и биомассы макрозообентоса, исследуемых

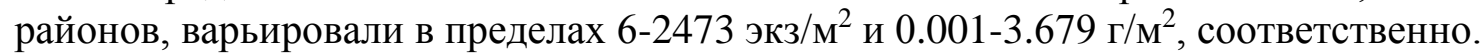

Наибольшие численность и биомасса макрозообентоса отмечены в акватории Карадага. Ранжированный ряд по этим показателям возглавляли полихеты, их вклад в общую численность макрозообентоса составил $54 \%$, в общую биомассу $-60 \%$.

Наиболее богатый таксономический состав зарегистрирован на участке псевдолиторали Опукского природного заповедника, там отмечены шесть таксономических групп: Polychaeta, Mollusca, Crustacea, Platyhelminthes, Nemertea, Oligochaeta. На «Мысе Мартьян» и на Казантипе - наименьшее количество таксонов.

Учитывая, что все исследуемые участки относятся к заповедной зоне, а это предполагает минимальную антропогенную нагрузку на них, различие в таксономическом составе может быть вызвано неодинаковым гранулометрическим составом. На Опуке широкие песчаные пляжи с преобладанием среднего и мелкого песка, поэтому здесь более благоприятные условия для обитания гидробионтов. На участках «Мыса Мартьян» и Казантипа преобладают крупные фракции грунта: средний, мелкий гравий и крупный 
песок, поэтому здесь обнаружены гидробионты, которые приспособлены обитать в таких сложных условиях, т.к. под воздействием волн крупные фракции грунта перетирают бентосных животных, приводя их к гибели.

Наибольшее видовое разнообразие зарегистрировано на участке псевдолиторали Опукского природного заповедника: Polychaeta (5 видов), Mollusca (2 вида), Crustacea (5 видов), также зарегистрированы Oligochaeta, Platyhelminthes и Nemertea (не идентифицированные до вида таксоны считали, как один вид) (табл. 2).

Таблица 2.

Таксономический состав макрозообентоса зоны псевдолиторали заповедников

\begin{tabular}{|c|c|c|c|c|}
\hline \multicolumn{5}{|c|}{ Крыма } \\
\hline \multirow[t]{2}{*}{ Таксон } & \multicolumn{4}{|c|}{ Районы исследования } \\
\hline & Мартьян & Карадаг & Опук & Казантип \\
\hline Polychaeta & $\mathrm{N} / \mathrm{B}$ & $\mathrm{N} / \mathrm{B}$ & $\mathrm{N} / \mathrm{B}$ & $\mathrm{N} / \mathrm{B}$ \\
\hline Microphthalmus fragilis Bobretzky, 1870 & 0 & $592 / 0.208$ & 0 & 0 \\
\hline Mysta picta (Quatrefages, 1866) & 0 & 0 & $5 / 0.003$ & 0 \\
\hline Namanereis pontica (Bobretzky, 1872) & 0 & 0 & $2 / 0.0002$ & 0 \\
\hline Pisione remota (Southern, 1914) & 0 & 0 & $4 / 0.005$ & 0 \\
\hline Polycirrus jubatus (Bobretzky, 1869) & 0 & $69 / 0.972$ & 0 & 0 \\
\hline Protodorvillea kefersteini (McIntosh, 1869) & 0 & $1 / 0.0001$ & 0 & 0 \\
\hline Protodrilus flavocapitatus (Uljanin, 1877) & 0 & 0 & $384 / 0.376$ & 0 \\
\hline Saccocirrus papillocercus (Bobretzky, 1872) & $9 / 2.09$ & $991 / 2.463$ & $4664 / 0.974$ & 0 \\
\hline Salvatoria clavata (Claparede, 1863) & 0 & $72 / 0.035$ & 0 & 0 \\
\hline \multicolumn{5}{|l|}{ Crustacea } \\
\hline Apherusa bispinosa (Bate, 1857) & 0 & 0 & $2 / 0.0005$ & 0 \\
\hline \multicolumn{5}{|l|}{ Apohyale prevostii (Milne Edwards, 1830) } \\
\hline Chondrochelia savignyi (Kroyer, 1842) & 0 & 0 & 0 & $3 / 0.0001$ \\
\hline Echinogammarus foxi (Schellenberg, 1928) & $122 / 0.051$ & $43 / 0.085$ & $2 / 0.0004$ & $2520 / 0.978$ \\
\hline Echinogammarus ischnus (Stebbing, 1899) & $79 / 0.153$ & 0 & 0 & 0 \\
\hline Echinogammarus olivii Milne Edwards, 1830 & $2271 / 1.512$ & $272 / 0.113$ & 0 & 0 \\
\hline Echinogammarus sp. & 0 & $158 / 0.051$ & $4 / 0.0002$ & 0 \\
\hline Eurydice pontica (Czerniavsky, 1868) & 0 & 0 & $16 / 0.005$ & $3 / 0.0007$ \\
\hline Eurydice dollfusi Monod., 1930 & 0 & $17 / 0.022$ & 0 & 0 \\
\hline Gastrosaccus sanctus (Van Beneden, 1861) & 0 & 0 & $2 / 0.006$ & 0 \\
\hline Hyale perieri (Lucas, 1849) & $1 / 0.002$ & 0 & 0 & 0 \\
\hline Hyale schmidti (Heller, 1866) & $1 / 0.003$ & 0 & 0 & 0 \\
\hline Idotea balthica (Pallas, 1772) & 0 & 0 & 0 & $7 / 0.004$ \\
\hline Lekanesphaera hookeri (Leach, 1814) & 0 & $22 / 0.061$ & 0 & $86 / 0.154$ \\
\hline Melita palmata (Montagu, 1804) & 0 & $8 / 0.003$ & 0 & 0 \\
\hline Monocorophium acherusicum (Costa, 1853) & 0 & 0 & 0 & $44 / 0.006$ \\
\hline Orchestia gammarella (Pallas, 1766) & 0 & 0 & 0 & $192 / 0.428$ \\
\hline Pontogammarus maeoticus (Sovinsky, 1894) & 0 & 0 & 0 & $3 / 0.007$ \\
\hline Tylos ponticus Grebnitzky, 1874 & 0 & 0 & $4 / 0.012$ & 0 \\
\hline \multicolumn{5}{|l|}{ Mollusca } \\
\hline Donacilla cornea (Poli, 1791) & 0 & 0 & $159 / 53.513$ & 0 \\
\hline Mytilaster lineatus (Gmelin, 1790) & 0 & 0 & $2 / 0.011$ & 0 \\
\hline Platyhelminthes & $6 / 0.001$ & $220 / 0.052$ & $6291 / 0.561$ & $814 / 0.041$ \\
\hline Nemertea & 0 & $213 / 2.08$ & $1368 / 0.108$ & 0 \\
\hline Oligochaeta & 0 & 0 & $1368 / 0.059$ & $1293 / 0.016$ \\
\hline
\end{tabular}

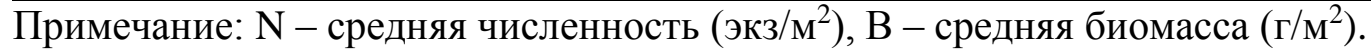


На участке псевдолиторали Опука обнаружены не только животные, типичные для этой зоны (полихеты: M. picta, N. pontica, P. remota, P. flavocapitatus, S. papillocercus; ракообразные: E. foxi, E. pontica, G. sanctus, T. ponticus; моллюски D. cornea), но и представители макрозообентоса, обычно обитающие в прибрежной зоне на водорослях ракообразные A. bispinosa и моллюски M. lineatus) (Мокиевский, 1949; Грезе, 1977; Киселёва, и др., 2009; Ковалёва и др., 2014;).

Среди полихет доминировали $S$. papillocercus, средняя численность которых достигала 4664 экз $/ \mathrm{M}^{2}$. Обычно саккоциррус обитает на крупнозернистом песке от 0 м до глубины 1м, его численность может значительно колебаться в зависимости от изменения состава грунта или гидрологического режима (Киселева, 2004; Копий, Лисицкая, 2012).

Ракообразные отмечены в единичных экземплярах, наибольшая численность $\left(16\right.$ экз $\left./ \mathrm{M}^{2}\right)$ зарегистрирована у изоподы $E$. pontica. Этот нектобентический псаммофильный вид, обычно обитает в прибрежном песке зоны заплеска, но также может встречаться в ночном планктоне (Грезе, 1985).

Моллюски представлены двумя видами - единичными экземплярами M. lineatus, которые обычно населяют различные биотопы от уреза воды до большой глубины и двустворчатым моллюском $D$. cornea, для которого характерно обитание на участке псевдолиторали (Копий, 2012; Мурина и др., 2006). Средняя численность донациллы была невысокой - 159 экз $/ \mathrm{m}^{2}$, поэтому ее вклад в общую численность не велик - всего $1 \%$, но для общей биомассы макрозообентоса роль D. cornea значительна - ее вклад составил $96 \%$.

Также на м. Опук зарегистрированы Oligochaeta, Platyhelminthes и Nemertea, их вклад в общую численность макрозообентоса составил $63 \%$, в биомассу $-1 \%$.

В зоне псевдолиторали Опука обнаружено наибольшее количество гидробионтов, обитающих только на данном участке: 4 вида полихет, 3 вида ракообразных и 2 вида моллюсков. Все животные, кроме полихеты P. flavocapitatus и двустворчатого моллюска D. cornea встречены в единичных экземплярах.

Наименьшее число видов макрозообентоса отмечено на «Мысе Мартьян»: 1 вид Polychaeta, 5 видов Crustacea и Platyhelminthes. На этом участке обнаружены животные, типичные для зоны псевдолиторали: полихеты S. papillocercus, ракообразные (амфиподы из семейства Gammaridae (E. foxi, E. ischnus, E. olivii) и Hyalidae (H. perieri, H. schmidti)) и Platyhelminthes (Мокиевский, 1949; Водяницкий, 1969; Грезе, 1985; Киселёва и др., 2009; Ковалёва и др., 2014;).

Полихеты представлены единичными экземплярами S. papillocercus. Среди ракообразных по численности доминировали E. olivii $(2271$ экз/м²), которые являются типично прибрежной формой. Они обитают в самой верхней зоне сублиторали на галечных или песчаных грунтах, локализуясь у самого уреза воды и укрываясь в углублениях нижней поверхности камней. В штормовую погоду раки отходят от уреза воды на глубину до десяти метров (Грезе, 1985). Данный вид внес значительный вклад в общую численность и биомассу макрозообентоса (91\% и 40\%, соответственно).

На м. Мартьян зарегистрировано наименьшее количество гидробионтов (3 вида амфипод), обитающих только на данном участке - два вида рода Hyale (H. perieri, H. schmidti) и один вид рода Echinogammarus (E. ischnus). Для всех обнаруженных видов ракообразных характерно обитание в прибойной зоне: хуалиды обитают под влажными выбросами выше и ниже уреза воды и в прибрежном биоценозе цистозиры, E. ischnus - на плотном субстрате, преимущественно среди камней, часто у уреза воды (Водяницкий, 1969; Грезе, 1977).

Во всех исследуемых районах зарегистрированы амфиподы $E$. foxi и Platyhelminthes. Численность E. foxi была максимальной в Казантипском природном 
заповеднике и достигала 2520 экз/м². Мы предполагаем, что высокая численность $E$. foxi связана с гранулометрическим составом грунта в этом районе, т.к. известно, что данный вид обычно предпочитает обитать в зоне заплеска на галечно-песчаном грунте (Гринцов, Лисицкая, 2016).

Максимальная численность Platyhelminthes (6291 экз/ $\left.\mathrm{M}^{2}\right)$ зарегистрирована на Опуке и это можно связать с тем, что саккоциррусный песок - характерная для турбеллярий среда обитания, а амфиподы в выбросах водорослей - пища для них, т.к. турбеллярии являются хищниками и способны питаться мелкими беспозвоночными, в том числе и ракообразными, предпочтение отдается амфиподам (Мурина, 1974).

Следует отметить неравномерное распределение бентосных животных по горизонтам псевдолиторали (рис. 2). На Карадаге наибольшее количество (70\% общей численности макрозообентоса) гидробионтов отмечено ниже уреза воды. Ранжированный ряд по численности возглавляли ракообразные (1304 экз/м²), для которых характерно обитание в прибрежных водорослях (Грезе, 1977). В остальных районах наибольшее количество гидробионтов отмечено на урезе воды: Мартьян $-46 \%$, Опук $-50 \%$, Казантип $-65 \%$ общей численности макрозообентоса.

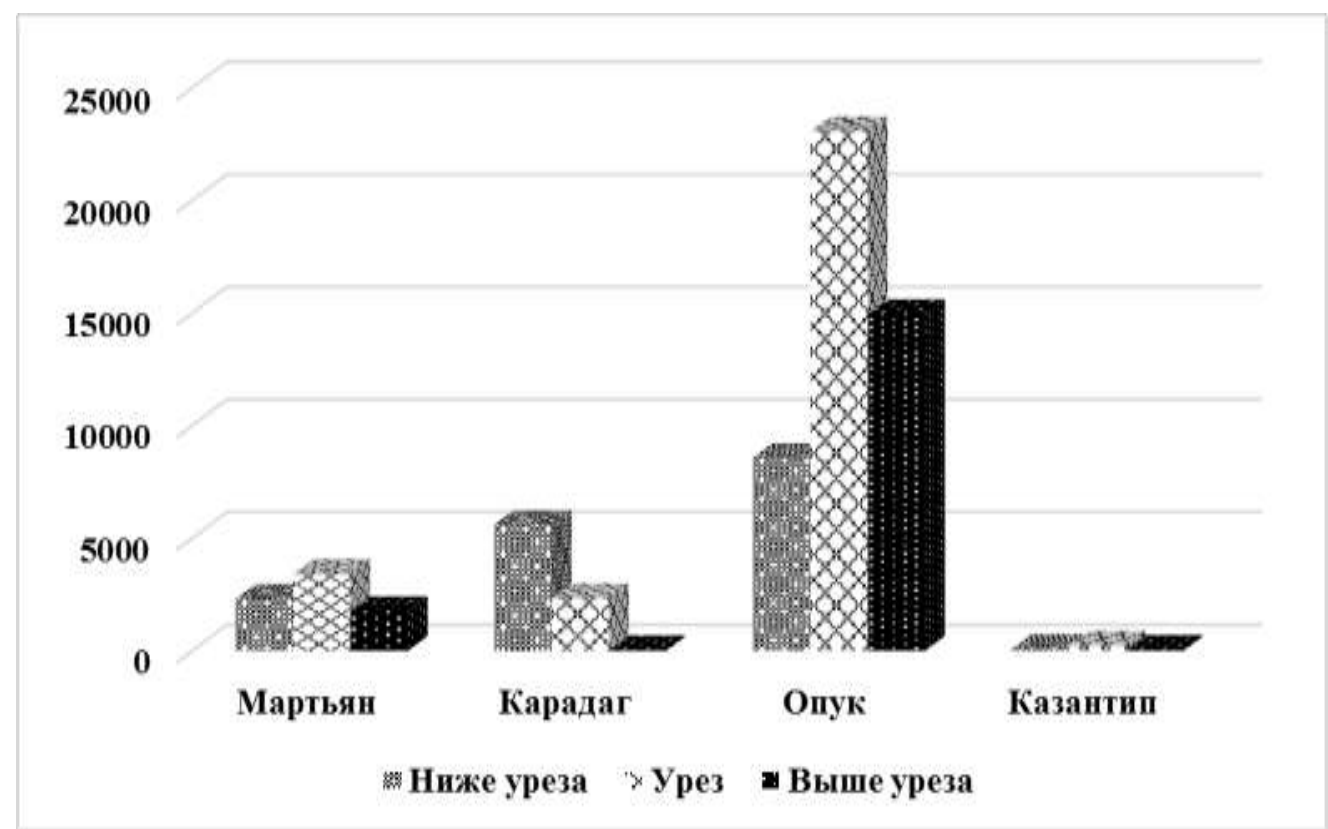

Рис. 2. Средняя численность (экз/ $\mathrm{M}^{2}$ ) макрозообентоса по горизонтам в зоне псевдолиторали заповедников Крыма.

На всех исследуемых участках, за исключением Опука, на горизонте выше уреза воды отмечена самая низкая численность гидробионтов. На Опуке выше уреза воды ранжированный ряд по численности возглавляли полихеты S. papillocercus - вид, адаптированный к сложным условиям зоны псевдолиторали (Копий, Лисицкая, 2012).

Мы предполагаем, что такое распределение макрозообентоса по горизонтам псевдолиторали связано с различием условий обитания. Ниже уреза и на урезе воды условия наиболее стабильны, отсутствует осушение, не воздействуют такие факторы, как инсоляция и высокая температура. Поэтому в летнее время гидробионты предпочитают нижний горизонт псевдолиторали или урез воды, выше уреза воды, в основном, встречаются представители макрозообентоса, которые способны избежать негативного воздействия, зарываясь глубже в грунт или перемещаясь в более благоприятные условия, где воздействие этих факторов минимизируется. 
Исследование трофической структуры макрозообентоса показало наличие пяти трофических групп: детритофаги, фитофаги, полифаги, плотоядные и сестонофаги (рис. 3).
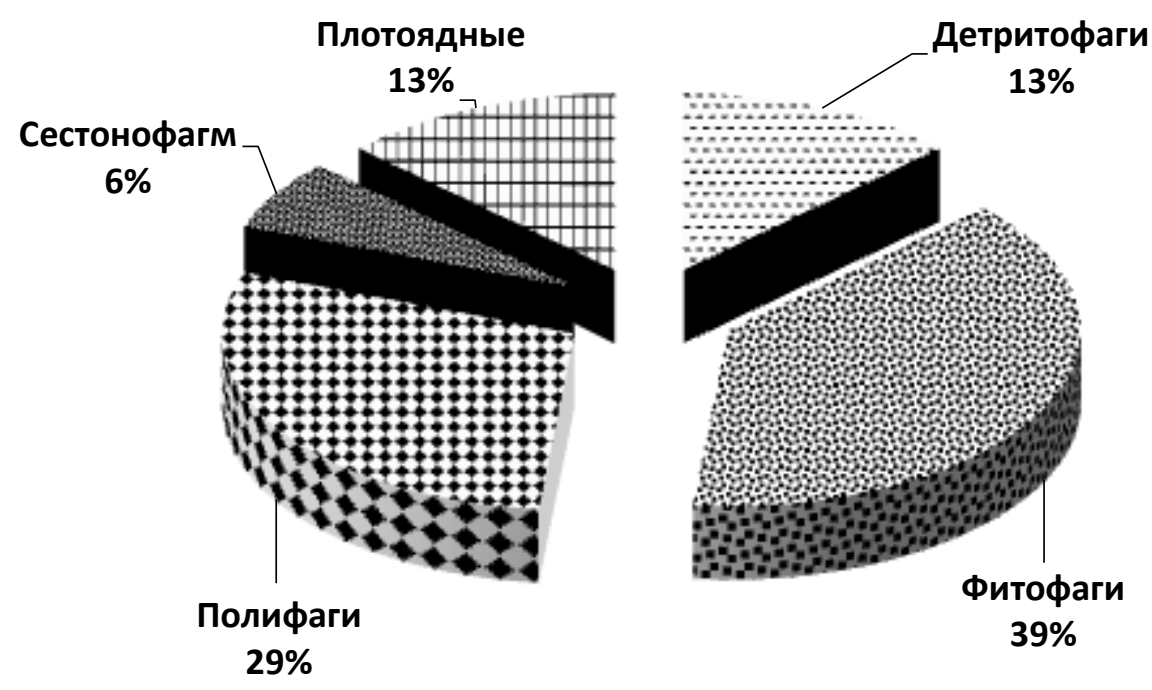

Рис. 3. Трофическая структура макрозообентоса в зоне псевдолиторали заповедников Крыма

Самая многочисленная группа - фитофаги, к которой принадлежат 12 видов гидробионтов (5 видов полихет и 7 видов ракообразных), на их долю приходится 39\% общего количества зарегистрированных видов. К самой малочисленной группе сестонофагов относится всего 2 вида двустворчатых моллюсков - D. cornea и M. lineatus.

Bce трофические группы зарегистрированы на Опуке, наименьшее число трофических групп - на Мартьяне (обнаружены только фитофаги и хищники).

\section{Выводы}

Таким образом, в зоне псевдолиторали заповедников Крыма идентифицированы представители макрозообентоса, относящиеся к разным таксономическим категориям: Polychaeta, Mollusca Crustacea, Platyhelminthes, Nemertea и Oligochaeta.

Наибольшие численность и биомасса макрозообентоса отмечены в акватории Карадага. Наиболее богатый таксономический и видовой состав зарегистрированы на участке псевдолиторали Опукского природного заповедника: Polychaeta (5 видов), Mollusca (2 вида), Crustacea (5 видов), Oligochaeta, Platyhelminthes и Nemertea.

Наименьшее число видов макрозообентоса отмечено на «Мысе Мартьян»: Polychaeta (1 вид), Crustacea (5 видов) и Platyhelminthes.

Распределение макрозообентоса по горизонтам псевдолиторали показало, что гидробионты предпочитают участки ниже уреза и на урезе воды, где условия обитания для них наиболее благоприятны.

Исследование трофической структуры макрозообентоса показало наличие пяти трофических групп: детритофаги, фитофаги, полифаги, плотоядные и сестонофаги. Все трофические группы зарегистрированы на Опуке, наименьшее число трофических групп на Мартьяне (обнаружены только фитофаги и хищники).

Благодарность. Автор выражает искреннюю благодарность м.н.с. Бондаренко Л.В. за помощь в сборе материала и обработку данных по ракообразным. 


\section{Список литературы}

1. Водяницкий В.A. Определитель фауны Черного и Азовского морей. - К.: Наукова думка, 1969. - T. 2. $-535 \mathrm{c}$.

2. Грезе В.Н., Поликарпов Г.Г., Романенко В.Д. и др. Природа Украинской ССР. Моря и внутренние воды. - К: Наук. думка, 1987. - 224 с.

3. Грезе И.И. Амфиподы Черного моря и их биология. - К: Наукова думка, 1977. - 156 с.

4. Грезе И.И. Фауна Украины. Высшие ракообразные. Бокоплавы. - К.: Наукова думка, 1985. - Т. 26. - Вып. 5. - 172 с.

5. Гринцуов B.A., Лисицкая Е.В. Видовое разнообразие беспозвоночных сообщества обрастания зоны заплеска района Карадага // Заповедники Крыма. Биологическое и ландшафтное разнообразие, охрана и управление: материалы VIII Международной науч.-практ. конф. (Симферополь, 28-30 апр. 2016 г.). - Симферополь, 2016. - С. $287-$ 289.

6. Загороднюк Н.В. Бріофлора Опукського природного заповідника // Заповедники Крыма. Теория, практика и перспективы заповедного делав Черноморском регионе: материалы V Междунар. науч.-практ. конф. (Симферополь, 22 - 23 окт. 2009 г.). - Симферополь, 2009. - C. 165-171.

7. Зайцев Ю.П., Поликарпов Г.Г. Экологические процессы в критических зонах Черного моря (синтез результатов двух направлений исследований с середины XX до начала XXI веков) // Морской экологический журнал. - 2002. - Т. 1. - № 1. - С. 33-55.

8. Зенкович В.П. Берега Черного и Азовского морей. - М.: Госуд. изд-во географической литературы, 1958. - 376 с.

9. Киселёва Г.А., Коновалов В.С., Лапченко А.А., Колова К.А. Видовой состав и динамика макрозообентоса в ассоциациях водорослей Карадагского природного заповедника // Экосистемы, их оптимизация и охрана. - 2009. - Вып. 20. - С. 57-66.

10. Киселёва М.И. Многощетинковые черви (Polychaeta) Чёрного и Азовского морей. Апатиты: Изд-во Кольского научн. центра РАН, 2004. - 409 с.

11. Ковалёва М.А., Болтачева Н.А., Макаров М.В., Бондаренко Л.В. Обрастания естественных твердых субстратов (скал) акватории Карадагского природного заповедника // Экосистемы, их оптимизация и охрана. - 2014. - Вып. 10 - С. 77-81.

12. Копий В.Г., Лисицкая E.B. Современное состояние популяции Saccocirrus papillocercus Bobretzky, 1872 (Polychaeta: Saccocirridae) прибрежной зоны Крыма (Чёрное море) // Морской экологический журнал. - 2012. - Т. 11. - № 4. - С. 39-44.

13. Копий В.Г. Современное состояние поселений Donacilla cornea в прибрежных районах северо-западной части Чёрного моря // Наук. зап. Терноп. нац. пед. ун-ту. Сер.: Біологія. - 2012. - № 2 (51). - С. 140-144.

14. Маслов И.И., Крайнюк Е.С., Саркина И.С., Костин С.Ю., Сергеенко А.Л. Основные направления и результаты научной и природоохранной деятельности отдела охраны природы НБЦ-НИЦ, природного заповедника «Мыс Мартьян» (1973-2010 гг.) // Бюллетень Никитского ботанического сада. - 2011. - Вып. 100. - С. 29-39.

15. Миронов О.Г. Санитарно-биологические исследования в прибрежной акватории Севастополя. - Севастополь: ЭКОСИ-Гидрофизика, 2009. - 192 с.

16. Мокиевский О.Б. Фауна рыхлых грунтов литорали западных берегов Крыма // Тр. ИОАН. - 1949. - Т. 4. - С. 124-159.

17. Морозова А.Л., Смирнова Ю.Д., Гасников С.В. Влияние природных и антропогенных факторов на трансформацию морских прибрежных экосистем Карадагского заповедника // Материалы III Междунар. конф. / Юж. науч.-иссл. ин-т мор. рыб. хоз-ва и океаногр. (ЮгНИРО), (Керчь, 9 - 11 окт., 2007 г.). - Керчь, 2007. - С. 61- 67. 
18. Мурина B.B. К биологии черноморской турбеллярии Cercyra hastata Schmidt // Биология моря. - 1974. - Вып. 4. - С. 3-22.

19. Мурина В.В., Евстигнеева И.К., Гриниоа В.А., Лисиџкая Е.В., Ковригина Н.П., Чекменева Н.И., Богданова Т.А., Танковская И.Н. К изучению биоразнообразия прибрежной акватории Казантипского природного заповедника и прилегающих районов // Труды Никитского ботанического сада. - 2006. - Т. 126. - С. 295-305.

20. Садогурська C.O. Анотований список Cуanoprokaryota морської кам'янистої супраліторалі природного заповідника "Мис Мартьян" // Чорноморський ботанічний журнал - 2013 - 9 (1). - С. 125-138.

\section{MACROZOOBENTHOS IN THE ZONE PSEUDOLITTORAL OF THE CRIMEA RESERVES \\ Kopiy V. G.}

Institute of Marine Biological Research RAS (former IBSS NASU), Sevastopo,l Russian Federation e-mail:verakopiy@gmail.com

The study is based on material collected in areas mediolittoral Karadag (July 2008), Kazantip, Opuksky (August 2013), "Cape Martian" (August 2014) natural reserves. Taxonomic and species composition of macrozoobenthos mediolittoral Crimean reserves is presented and the dominant species are described based on generalization of obtained data. A comparative analysis of quantitative parameters of macrozoobenthos in the studied areas was made. The horizontal distribution of animals in relation to the water's edge and the trophic structure of macrozoobenthos communities of the zone of mediolittoral Crimean reserves was nvestigated.

Key words: macrozoobenthos, mediolittoral, Crimea reserves, Black Sea.

Поступила в редакиию 06.03.2017 г. 